\title{
Oxidation of an internally solvated allylic lithium compound: NMR and X-ray crystallography
}

\author{
Gideon Fraenkel*, Roland Fleischer, and Hua Liu \\ Department of Chemistry, The Ohio State University, $100 \mathrm{~W} .18^{\text {th }}$ Avenue, \\ Columbus, OH 43210, USA \\ E-mail: Fraenkel@mps.ohio-state.edu
}

\begin{abstract}
Dedicated to Professor Gerasimos Karabatsos on his $70^{\text {th }}$ birthday
(received 07 Mar 03; accepted 24 Jun 03; published on the web 26 Jun 03)
\end{abstract}

\begin{abstract}
The structure in solution of an allylic lithium compound with attached chiral ligand, 4, is shown by NMR to be internally solvated, partially delocalized and with a small detectable C-Li covalence. Crystallization of $\mathbf{4}$ in the presence of $\mathrm{O}_{2}$ produces a 1:1 complex of $\mathbf{4}$ with its alkoxide oxidation product 9. X-ray crystallography reveals the allylic lithium part of this complex to be fully delocalized.
\end{abstract}

Keywords: Allylic lithium compound, internally solvated, chiral auxiliary, NMR, X-ray

\section{Introduction}

The allyl anion is the simplest of the conjugated carbanions. Numerous chemical, ${ }^{1}$ spectroscopic ${ }^{2}$ and calculational ${ }^{3}$ and crystallographic ${ }^{4}$ studies have established that solvated allylic lithium compounds are delocalized with the coordinated lithium centered and normal with respect to the allyl plane. By contrast, NMR data for the unsolvated allylic lithium compounds $\mathbf{2 a}$, $2 \mathbf{b}$ supports a more covalent structure. ${ }^{5}$ Structures which exhibit a degree of delocalization between $\mathbf{1}$ and $\mathbf{2}$ are not well known. Just recently our studies of some allylic lithium compounds with attached ligands showed these compounds to be internally solvated. ${ }^{6}$ It was concluded that the length ofthe tether restricted the site of lithium coordination from normal to the allyl plane towards thisplane. Compared to $\mathbf{1}$ the result is to introduce some increase in the C-Li covalency and a 


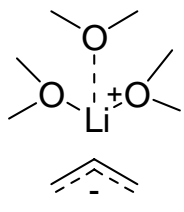

1

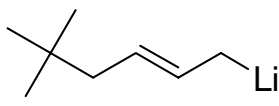

$2 a$

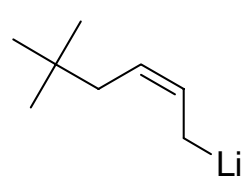

2b

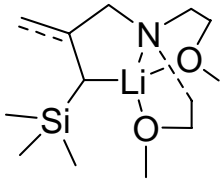

3

decrease in the degree of delocalization within the allylic moiety, see $3 .{ }^{6}$ Compounds such as $\mathbf{3}$ incorporate an unusual and previously unreported mode of partial delocalization and partial C-Li bonding which lies between the previously recognized structures $\mathbf{1}$ and $\mathbf{2}$.

\section{Results and Discussion}

A common hazard encountered in the chemistry and handling of many organolithium compounds is their reactions with adventitious oxygen. ${ }^{7}$ The resulting lithium alkoxides reduce the reactivity of remaining organolithium compounds. It has been proposed that this reduced reactivity is due to complexation between "RLi" and "ROLi" species, respectively. A number of such complexes have been reported based on $\mathrm{NMR}^{8}$ and X-ray crystallographic studies. ${ }^{9}$

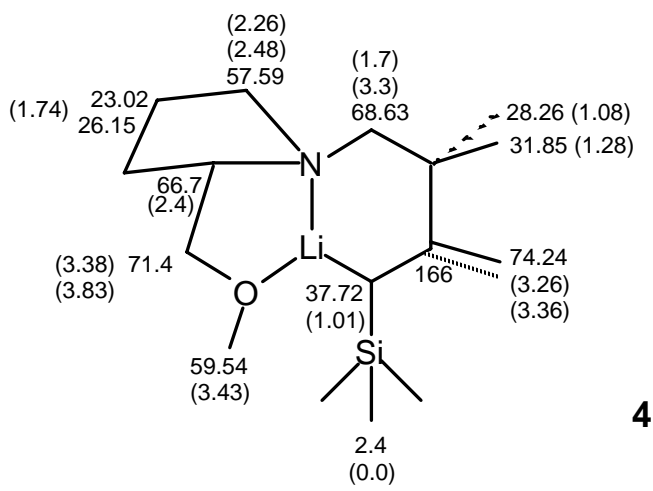

Herein we describe some studies of a silyl substituted allylic lithium compound with an attached chiral auxiliary, the (S)-2-methoxymethylpyrollidino ligand. We show below how structure 4 (with ${ }^{13} \mathrm{C}$ and ${ }^{1} \mathrm{H}$ shifts) describes the compound in solution, crystals have been isolated which consist of a 1:1 complex of $\mathbf{4}$ with the lithium alkoxide formed by reaction of $\mathbf{4}$ with adventitious oxygen.

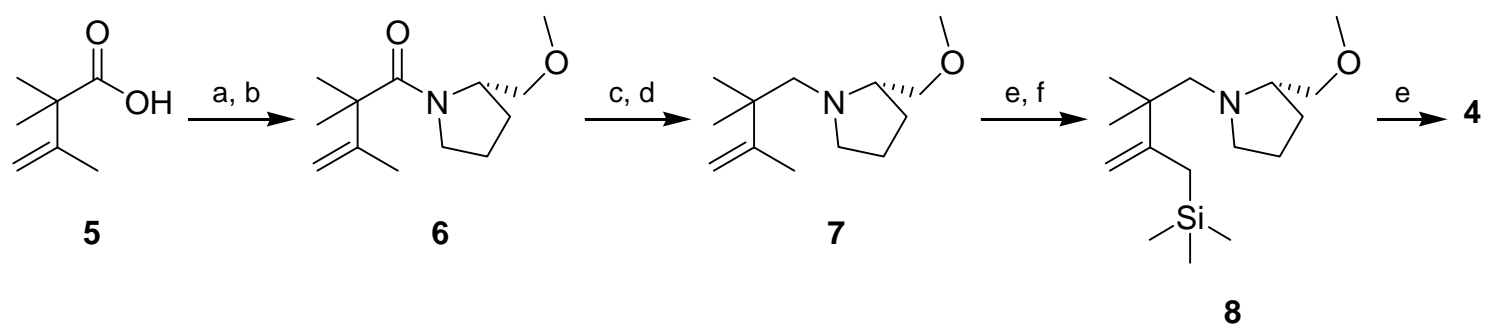

a: $\mathrm{SOCl}_{2}$; b: (S)-2-methoxymethylpyrolidine; c: $\mathrm{LiAlH}_{4} ; \mathrm{d}: \mathrm{H}^{+}, \mathrm{H}_{2} \mathrm{O}$; e: $n$-BuLi, $\mathrm{Et}_{2} \mathrm{O}$; f: TMSCl.

\section{Scheme 1}


Treatment of compound 8 (Scheme 1) with $n$-butyllithium in diethyl ether provides the lithium compound $\mathbf{4}$. Structure $\mathbf{4}$ is proposed on the basis of NMR data obtained from a solution of the compound in diethylether- $d_{10}$. The ${ }^{13} \mathrm{C}$ and $\left({ }^{1} \mathrm{H}\right)$ shifts listed around $\mathbf{4}$ were assigned from a combination of ${ }^{13} \mathrm{C}$ DEPT, proton-proton COSY and ${ }^{13} \mathrm{C},{ }^{1} \mathrm{H}$ COSY experiments, respectively. The 1-C and $3-\mathrm{C}{ }^{13} \mathrm{C}$ allyl shifts at $\delta 37.72$, and $\delta 74.87$, respectively, together with the observation of one bond ${ }^{13} \mathrm{C} 1{ }^{7} \mathrm{Li}$ spin coupling of $8.7 \mathrm{~Hz}$ implies that species 4 is partially delocalized with a small detectable 1-C-Li covalence. In addition, bimolecular C1-Li exchange is slow at $200 \mathrm{~K}$ relative to the NMR time scale. The equal quartet observed for the ${ }^{13} \mathrm{C}$ resonance of lithium bound carbon most likely indicates that $\mathbf{4}$ is a monomer. These results resemble data for $\mathbf{3}$ whose ${ }^{13} \mathrm{C}$ allyl shifts lie between those for the well known solvated delocalized structure $\mathbf{1}$ and the unsolvated localized structures $\mathbf{2 a}$, $\mathbf{2} \mathbf{b}$.

With increasing temperature above $230 \mathrm{~K}$ the ${ }^{13} \mathrm{C}$ NMR quartet due to ${ }^{7} \mathrm{Li}$ bound carbon of 4 in diethyl ether- $\mathrm{d}_{10}$ solution progressively averages to a single line by $330 \mathrm{~K}$. This is clearly the result of increasingly fast bimolecular C-Li exchange. ${ }^{6}$ Also, on cooling below $230 \mathrm{~K}$ the four components of this multiplet selectively broaden and average to a single line which reflects the operation of fast ${ }^{7} \mathrm{Li}$ electric quadrupole induced quadrupole relaxation. ${ }^{10}$

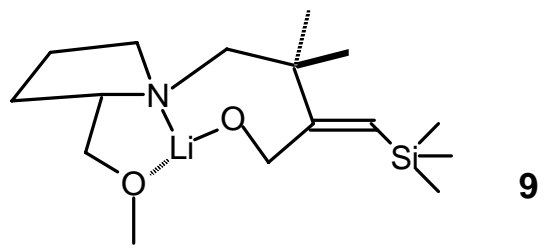

X-ray crystallography of the material produced in experiments to generate $\mathbf{4}$ in hexane yielded the structure displayed in Figure $1 .^{11}$ These crystals appear to consist of a lithiumbridged 1:1 complex of $\mathbf{4}$ with the lithium alkoxide $\mathbf{9}$. The solid state complex of $\mathbf{9}$ with $\mathbf{4}$ will henceforth be referred to as $\mathbf{1 0}$. Figure 2 displays a partial structure of $\mathbf{1 0}$ which highlights the two allylic moieties and the bridge which connects the two. 


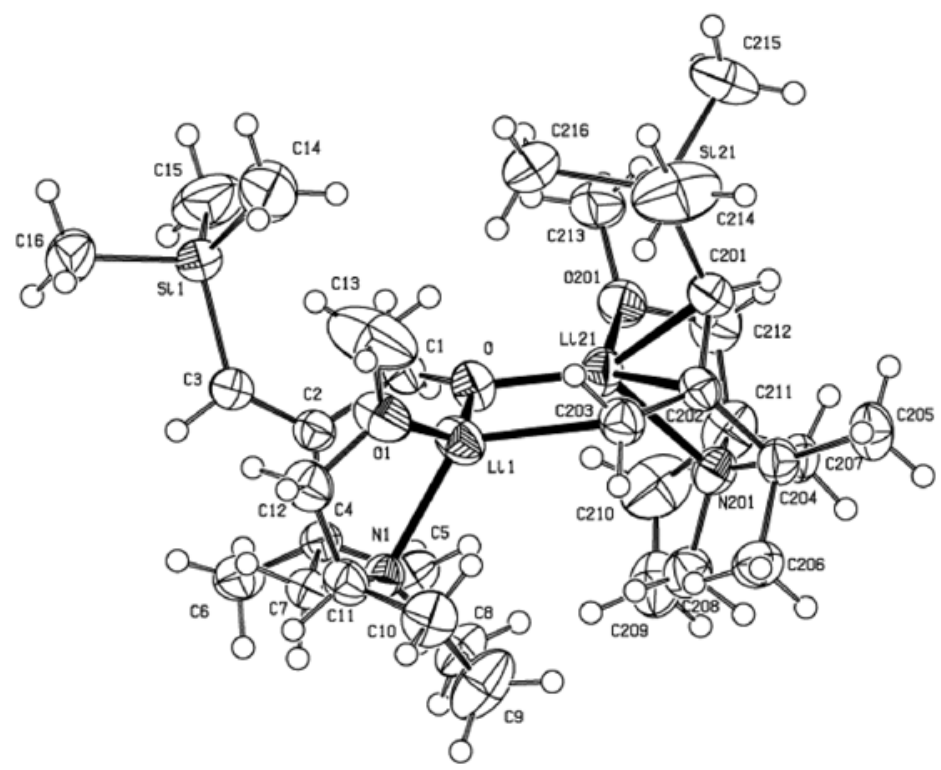

Figure 1. Skeleton of $\mathbf{1 0}$ with $30 \%$ probability ellipsoids omitting the hydrogens to emphasize the allyl moieties and lithium coordination.

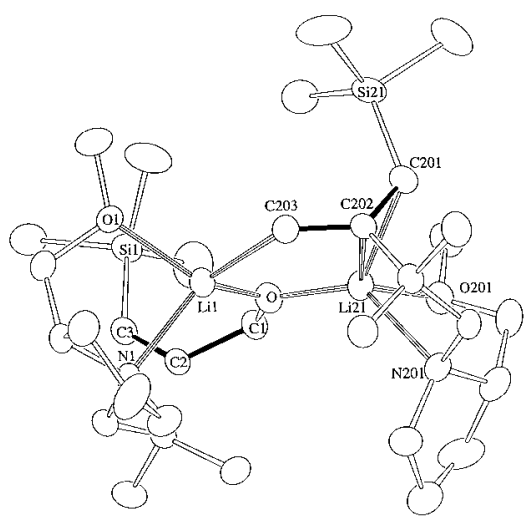

Figure 2. ORTEP diagram of compound $\mathbf{1 0}$ with 50\% probability ellipsoids.

Inspection of Figures 1 and 2 reveals that each lithium is fully coordinated to a separate $(S)$ 2-methoxymethylpyrrolidino moiety. The allylic alkoxide part of $\mathbf{1 0}$ shows typical single (C1C2, $1.519 \AA$ ) and double (C2-C3, $1.341 \AA$ ) bonds. Apparently $\mathrm{O}_{2}$ has reacted at the methylene terminus of 4 since the TMS group is at C3 (Figure 1). Further, the latter TMS group is cis to $\mathrm{CH}_{2} \mathrm{OLi}$, which places its trans to the substituent ligand at $\mathrm{C} 2$. Note that externally solvated 1TMS-allyllithium has been shown from NMR data to adopt the exo-TMS structure 11. ${ }^{12}$ In fact, among the many reactions of $\mathbf{1 1}$ with electrophiles $\mathrm{E}^{+}$, which have been reported, the products have almost always been shown to be trans, 12 (Scheme 2). ${ }^{13}$ The exception here is most likely due to potential steric interactions of TMS with the ligand substituent at C2. 


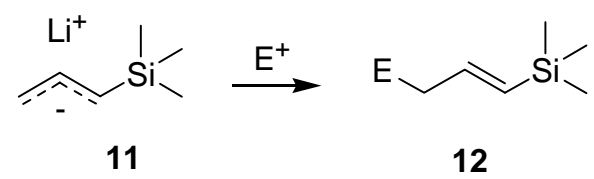

\section{Scheme 2}

As noted above, compound $\mathbf{4}$ in solution adopts the internally solvated partly delocalized structure shown, 4. This is similar to structures determined for most internally solvated allylic lithium compounds we have investigated ${ }^{6}$ so far, both in solution and in the solid state. By contrast the 1-TMS-allylic lithium part of $\mathbf{1 0}$ is delocalized with C201-C202 and C202-C203 bond lengths of 1.401 and 1.395, $\AA$ respectively. Lithium (21) is sited $2.225 \AA$ normal to the allyl plane, $0.81 \AA$ from C201 on the C201-C203 axis. Li21 is almost equidistant from C201 and C202, $2.374 \AA$ and $2.304 \AA$, respectively, and a little further, $2.700 \AA$, from C203. This delocalized structure is common to most externally solvated allylic lithium compounds which have been studied so far. ${ }^{4}$ However a terminal TMS substituent in these latter structures is almost always situated exo, see 11, whereas in the 1-TMS-allylic lithium part of $\mathbf{1 0}$ TMS is endo and in the allyl plane. The endo site places TMS on the less sterically hindered side of the C201-C202 bond, that is, trans to the ligand substituent at C202 and, interestingly lies $28^{\circ}$ off the allyl plane.

Table 1. Selected structural parameters, compound $\mathbf{1 0}$

\begin{tabular}{|c|c|c|c|c|c|c|c|c|c|c|c|}
\hline \multicolumn{3}{|c|}{ Bond lengths $[\AA]$} & \multicolumn{4}{|c|}{ Bond angles $\left[{ }^{\circ}\right]$} & \multicolumn{5}{|c|}{ Torsional angles $\left[{ }^{\circ}\right]$} \\
\hline $\mathrm{C} 1$ & $\mathrm{C} 2$ & 1.519 & $\mathrm{C} 3$ & $\mathrm{C} 2$ & $\mathrm{C} 1$ & 121.05 & $\mathrm{O}$ & $\mathrm{C} 1$ & $\mathrm{C} 2$ & C3 & +112.95 \\
\hline $\mathrm{C} 2$ & $\mathrm{C} 3$ & 1.341 & $\mathrm{C} 2$ & C3 & Si1 & 130.21 & $\mathrm{O}$ & $\mathrm{C} 1$ & $\mathrm{C} 2$ & $\mathrm{C} 4$ & -66 \\
\hline C3 & Si1 & 1.858 & C201 & C202 & C203 & 124 & Li1 & C203 & C202 & $\mathrm{Li} 21$ & -0.1 \\
\hline C201 & C202 & 1.401 & $\mathrm{Si} 21$ & C201 & C202 & 125.15 & C203 & Li1 & $\mathrm{O}$ & $\mathrm{Li} 21$ & -11.9 \\
\hline C202 & C203 & 1.395 & C202 & C203 & Li1 & 125.07 & Li1 & $\mathrm{O}$ & Li21 & C202 & -14.7 \\
\hline C201 & $\mathrm{Si} 21$ & 1.822 & Li1 & $\mathrm{O}$ & Li21 & 105.15 & $\mathrm{C} 4$ & $\mathrm{C} 2$ & C3 & Si1 & -174.5 \\
\hline Li1 & C203 & 2.762 & Li1 & $\mathrm{O}$ & $\mathrm{C} 1$ & 127.32 & $\mathrm{Si} 2$ & C201 & C202 & C204 & -152.84 \\
\hline Li1 & $\mathrm{O}$ & 1.767 & $\mathrm{C} 1$ & $\mathrm{O}$ & Li21 & 126.82 & & & & & \\
\hline Li1 & $\mathrm{O} 1$ & 2.017 & & & & & & & & & \\
\hline Li1 & N1 & 2.172 & & & & & & & & & \\
\hline Li21 & C201 & 2.374 & & & & & & & & & \\
\hline Li21 & C202 & 2.368 & & & & & & & & & \\
\hline Li21 & C203 & 2.766 & & & & & & & & & \\
\hline Li21 & $\mathrm{O}$ & 1.825 & & & & & & & & & \\
\hline Li21 & $\begin{array}{l}\text { O20 } \\
1\end{array}$ & 2.032 & & & & & & & & & \\
\hline Li21 & $\begin{array}{l}\text { N20 } \\
1\end{array}$ & 2.254 & & & & & & & & & \\
\hline
\end{tabular}


The two parts of $\mathbf{1 0}$ are connected by the near coplanar five atom bridge, -Li1-C203-C202Li21-O. Note that alkoxy oxygen and the $(\mathrm{Li1})(\mathrm{Cl})(\mathrm{Li} 21)$ bonding arrangement around it are coplanar, see Figure 2 and Table 1.

The reactivity of organolithium compounds is often reduced by alkoxide impurities which are generated from the reaction of adventitious dioxygen with the RLi reagent. It has been proposed though not established that this reduced reactivity of the RLi species is due to its complexation with lithium alkoxide. The present work establishes one such internally solvated RLi•ROLi complex which has been isolated and identified.

\section{Experimental Section}

General Procedures. All manipulations of organometallic compounds were carried out under an inert gas atmosphere, $\mathrm{N}_{2}$ or Ar. Solvents were dried over NaK alloy and distilled before use. NMR spectra were obtained using Bruker AM 250 or Avance 300 spectrometers respectively.

X-Ray crystallography. Metalation of 8 by $n$-butyllithium at $0{ }^{\circ} \mathrm{C}$ in a hexane/THF medium followed by $10 \mathrm{~h}$ of storage at room temperature produced crystals of $\mathbf{1 0}$. A sample of the crystalline material was removed from the mother liquor using standard Schlenk techniques, and coated with Paratone N, an inert oil. Crystals were handled under oil under a microscope. Suitable crystals were then mounted at the end of a glass fiber in a drop of Paratone $\mathrm{N}$ and then shock cooled on the diffractometer. All data were collected at $173 \mathrm{~K}$. Data were collected on a Euraf-Nonius diffractometer with a CCD area detector using graphite monochromatic $\mathrm{MOK}_{\alpha}$ radiation $(\lambda=0.71073 \AA)$. Structures were solved by direct methods with SHELXS-97. ${ }^{11}$ Structures were refined by full matrix least squares procedures on $\mathrm{F}^{2}$ using SHELXL-97. All non hydrogen atoms were refined anisotopically. Allylic and vinylic hydrogen atom positions were taken from the difference electron density map and refined freely. Other hydrogen atoms were positioned at ideal geometries and a riding model was employed in the refinement. The denoted $\mathrm{R}$ values are defined as follows:

$\mathrm{R} 1=\sum|| \mathrm{F}_{\mathrm{o}}|-| \mathrm{F}_{\mathrm{c}}|| /\left|\mathrm{F}_{\mathrm{o}}\right|$ $\mathrm{wR} 2=\left\{\sum \mathrm{w}\left(\mathrm{F}_{\mathrm{o}}{ }^{2}-\mathrm{F}_{\mathrm{c}}{ }^{2}\right)^{2} / \sum \mathrm{w}\left(\mathrm{F}_{\mathrm{o}}{ }^{2}\right)^{2}\right\}^{1 / 2} ; \mathrm{w}=1 /\left\{\sigma^{2}\left(\mathrm{~F}_{\mathrm{o}}{ }^{2}\right)+(\mathrm{g} 1 * \mathrm{P})^{2}+\mathrm{g} 2 * \mathrm{P}\right\} ; \mathrm{P}=\left(\mathrm{F}_{\mathrm{o}}{ }^{2}+2 \mathrm{~F}_{\mathrm{c}}{ }^{2}\right) / 3$

Selected bond lengths are presented in Table 1. Complete copies of the x-ray crystallographic data for compound $\mathbf{1 0}$ have been deposited with the Cambridge Crystallographic Centre, 12 Union Road, Cambridge CB2, 1LZ, UK, under compound number 155146.

Allylic lithium compounds, general method. Butlyllithium in hexane (3.13 mL, $1.6 \mathrm{M}, 5 \mathrm{mmol})$ was added slowly by syringe at $0{ }^{\circ} \mathrm{C}$ to a solution of the allyl compound $(5 \mathrm{mmol})$ in $10 \mathrm{~mL}$ freshly distilled dry, oxygen free diethyl ether. After addition was complete the mixture was allowed to 
warm to room temperature and then stirred for $1 \mathrm{~h}$. An aliquot $(1 \mathrm{~mL})$ of this solution was transferred into an NMR tube with attached joint and straight bore stopcock. All volatile material was removed in vacuo and then replaced by deuterated solvent diethyl ether- $d_{10}$ or THF- $d_{8}$. The latter was distilled from sodium over the vacuum line into the NMR tube. The sample tube was degassed via three freeze thaw cycles and then sealed off frozen with pumping.

Silylation of allylic lithium compounds. A freshly prepared sample of an allylic lithium compound was cooled to $-78{ }^{\circ} \mathrm{C}$ and chlorotrimethylsilane $(0.54 \mathrm{~g}, 0.64 \mathrm{~mL}, 5 \mathrm{mmol})$ was added slowly by syringe. Upon completion of the addition the mixture was allowed to warm to room temperature. The onset of reaction at $-40{ }^{\circ} \mathrm{C}$ was indicated by precipitation of $\mathrm{LiCl}$. The mixture was stirred for an additional $1 \mathrm{~h}$. Saturated aqueous $\mathrm{NaHCO}_{3}(10 \mathrm{~mL})$ was added to remove excess chlorotrimethylsilane. The aqueous phase was extracted twice with diethyl ether $(10 \mathrm{~mL})$. The combined non-aqueous phases were dried over $\mathrm{Na}_{2} \mathrm{SO}_{4}$, the solvent was removed, and the residue was distilled.

[4-[(2S)-2-(Methoxymethyl)pyrrolidin-1-yl]-2,3,3-trimethyl-1-(trimethylsilyl)butyl]lithium (4). Compound $\mathbf{8}^{14}(0.52 \mathrm{~g}, 2 \mathrm{mmol})$ was reacted with $n$-butyllithium $(1.25 \mathrm{~mL}, 1.6 \mathrm{M}, 2 \mathrm{mmol})$ in diethyl ether $(5 \mathrm{~mL})$ at $0{ }^{\circ} \mathrm{C}$. An NMR sample was prepared in diethyl ether- $d_{10}$ solution as indicated above. The reaction was also run in hexane to produce crystals. ${ }^{1} \mathrm{H}$ NMR $\left(\mathrm{Et}_{2} \mathrm{O}-d_{10}\right)$ : $\delta$ $3.43\left(\mathrm{OCH}_{3}\right), 3.38,3.83\left(\mathrm{OCH}_{2}\right), 3.26,3.36\left(=\mathrm{CH}_{2}\right) ; 2.4(\mathrm{NCH}), 2.26,2.48\left(\mathrm{NCH}_{2} \mathrm{CH}_{2}\right), 1.7,3.3$ $\left[{ }^{2} J=13 \mathrm{~Hz}, \mathrm{NCH}_{2}\left(\mathrm{CH}_{3}\right)_{2}\right] ; 1.01(\mathrm{CHSi}), 0.0\left[\mathrm{Si}\left(\mathrm{CH}_{3}\right)_{3}\right] ;{ }^{13} \mathrm{C}$ NMR: $\delta 166.2(\mathrm{C}-\mathrm{CH}), 74.24$ $\left(=\mathrm{CH}_{2}\right), 71.4\left(\mathrm{OCH}_{2}\right), 66.7(\mathrm{CHN}), 68.63\left[\mathrm{NCH}_{2} \mathrm{C}\left(\mathrm{CH}_{3}\right)_{2}\right), 59.54\left(\mathrm{OCH}_{3}\right), 57.59\left(\mathrm{NCH}_{2} \mathrm{CH}_{2}\right)$, $41.44\left[\mathrm{C}\left(\mathrm{CH}_{3}\right)_{2}\right], 37.72$ (CHSiLi), 28.26, 31,85, [( $\left.\left(\mathrm{CH}_{3}\right)_{2}\right], 23.02,26.15\left[\left(\mathrm{CH}_{2}\right)_{2}\right], 2.4\left[\mathrm{Si}\left(\mathrm{CH}_{3}\right)_{3}\right]$.

\section{Acknowledgments}

This research was supported by the National Science Foundation, Grant No. CHE 9615116 and the Newman Chair. RF thanks the Deutscher Akademischer Austausch-Dienst for fellowship support. We thank Dr. Charles Cottrell, Central Campus Instrumentation Center for untiring technical assistance.

\section{References}

1. (a) Wardell, J. L. Comprehensive Organometallic Chemistry; Wilkinson, G.; Stone, F. G. A.; Abel, E. W., Eds; Pergammon Press: Oxford, 1982; Vol. 7, p 97. (b) Seyferth, D.; Julia, T. F. J. Organometal. Chem. 1967, 8, C13.

2. (a) West, P.; Purmort, J. I.; McKinley, S. V. J. Am. Chem. Soc. 1968, 90, 797. (b) O’Brian, D. H.; Hart, A. J.; Russell, C. R. J. Am. Chem. Soc. 1975, 97, 4410. (c) Benn, R.; Rufinska, A. J. Organometal. Chem. 1982, 239, C19. (d) Bates, R. B.; Beavers, W. J. Am. Chem. Soc. 1974, 96, 5001. (e) Thompson, T. B.; Ford, W. T. J. Am. Chem. Soc. 1974, 101, 5459.

3. (a) Erusalimski, C. B.; Kormer, V. H. Zh. Org. Khim. 1984, 20, 2028. (b) Tidwell, E. R.; Russell, B. R. J. Organometal. Chem. 1974, 80, 175. (c) Clark, T.; Jemmis, E. D.; Schleyer, 
P. v. R.; Binkley, J. S.; Pople, J. A. J. Organometal. Chem. 1978, 150, 1. (d) Clarke, T.; Rhode, C.; Schleyer, P. v. R. Organometallics 1983, 2, 1344. (e) Bushby, R. J.; Tytho, M. P. J. Organometal. Chem. 1984, 270, 265. (f) Eikemma-Hommes, N. J. R. Van; Bühl, M.; Schleyer, P. v. R. J. Organometal. Chem. 1991, 409, 307.

4. (a) Koster, H.; Weiss, E. Chem. Ber. 1982, 115, 3422. (b) Schumann, U.; Weiss, E.; Dietrich, H.; Mahdi, W. J. Organometal. Chem. 1987, 322, 299. (c) Sebastian, J. F.; Grunwell, J. R.; Hsu, B. J. Organometal. Chem. 1974, 78, C1. (d) Boche, G.; Etzrodt, H.; Marsch, M.; Massa, H.; Baum, G.; Dietrich, H.; Mahdi, W. Angew. Chem. 1986, 98, 84. (e) Boche, G.; Fraenkel, G.; Cabral, J.; Harms, K.; Eikema-Hommes, N. J. P. Van.; Lorenz, J.; Marsch, M.; Schleyer, P. v. R. J. Am. Chem. Soc. 1992, 114, 1562.

5. (a) Fraenkel, G.; Halasa, A. F.; Mochel, V.; Stumpe, R.; Tate, D. J. Org. Chem. 1985, 50, 4563. (b) Glaze, W. H.; Jones. P. C. J. Chem. Soc. 1969, 1434. (c) Glaze, W. H.; Hanicac, J. E.; Moore, M. L.; Chandpuri, J. J. Organometal. Chem. 1972, 44, 39. (d) Glaze, W. H.; Hanicac, J. E.; Chandpuri, J.; Moore, M. L.; Duncan, D. P. J. Organometal. Chem. 1973, 51, 13. (e) Bywater, S.; Lachance, P.; Worsfold, D. J. J. Phys. Chem. 1975, 79, 2148.

6. (a) Fraenkel, G.; Qiu, F. J. Am. Chem. Soc. 1996, 118, 5828. (b) Fraenkel, G.; Qiu, F. J. Am. Chem. Soc. 1997, 119, 3571. (c) Fraenkel, G.; Duncan, J. H.; Wang, J. J. Am. Chem. Soc. 1999, 121, 432.

7. (a) Parker, K. A.; Koziski, K. A. J. Org. Chem. 1987, 52, 674. (b) Neumann, H.; Seebach, D. Chem. Ber. 1978, 111, 2785. (c) Cavigny, T.; Valette, G.; Larchevegne, M.; Normant, H. J. Organomet. Chem. 1978, 155, 147. (d) Meyer, W.; Seebach, D. Chem. Ber. 1980, 113, 1304. (e) Oliver, A. J.; Graham, W. A. G. J. Organomet. Chem. 1969, 19, 17. (f) Wardell, J. L. In Comprehensive Organometallic Chemistry; Wilkinson, G., Stone, F. G. A., Abel, E. W., Eds; Pergammon Press: Oxford, 1982; Vol 1, pp 43.

8. (a) Thomas, R. D.; Huang, H. J. Am. Chem. Soc. 1999, 121, 11239. (b) Delong, G. T.; Pannell, D. K.; Clarke, M. T.; Thomas, R. D. J. Am. Chem. Soc. 1993, 115, 7013, and references therein.

9. (a) Marsch, M.; Harms, K.; Lochmann, L.; Boche, G. Angew. Chem., Int. Ed. 1990, 29, 308. (b) Williard, P. G.; MacEwan, G. J. J. Am. Chem. Soc. 1989, 111, 7671.

10. Fraenkel, G.; Subramanian, S.; Chow, A. J. Am. Chem. Soc. 1995, 117, 6300.

11. (a) Sheldrick, G. M. Program for Crystal Structure Solution, version 1997. Acta. Cryst. A 1990, 461. (b) Sheldrick, G. M. "SHEXL” a Program for Crystal Structure Refinement, University of Göttingen, 1997.

12. (a) Fraenkel, G.; Chow, A.; Winchester, W. A. J. Am. Chem. Soc. 1990, 112, 1382. (b) Fraenkel, G.; Chow, A.; Winchester, W. A. J. Am. Chem. Soc. 1990, 112, 2582.

13. (a) Ayalon-Chass, D.; Ehlinger, E.; Magnus, P. J. Chem. Soc. Comm. 1977, 772. (b) Ehlinger, E.; Magnus, P. Tetrahedron Lett. 1980, 11; Ehlinger, E.; Magnus, P. J. Am. Chem. Soc. 1980, 102, 5004. (c) Corriu, R. J. P.; Lanneau, G. F.; Leclercq, D. J. Organomet. Chem. 1978, 144, 155. (d) Corriu, R. J. P.; Masse, J. J. Organomet. Chem. 1973, 57, C5. (e) Corriu, R. J. P.; Masse, J.; Samate, D. J. Organomet. Chem. 1975, 93, 71.

14. Fraenkel, G.; Liu, H.; Fleischer, R.; Chow, A. J. Am. Chem. Soc. submitted for publication. 